\title{
Das dificuldades da profissão professor, mas também de suas possibilidades
}

Ana Maria de Mattos Guimarães*

Dorotea Frank Kersch**

Deise Del Sent***

* Programa de Pós-

Gradução em Linguística RESUMO

Aplicada da Unisinos -

Universidade do Vale dos

Sinos

** Programa de Pós-

Gradução em Linguística

Aplicada da Unisinos -

Universidade do Vale dos Sinos

*** Rede Municipal de Ensino de Novo Hamburgo

A melhoria do desempenho dos alunos da rede pública em leitura e escrita vem se constituindo como um dos grandes desafios da escola brasileira. Em parceria com o município de Novo Hamburgo-RS, idealizamos um processo de formação continuada cooperativa no qual procura-se fazer com que o letramento acadêmico dos formadores interaja com as práticas sociais dos professores e seus alunos. No âmbito do projeto, ampliamos o conceito de sequência didática e pensamos o Projeto Didático de Gênero (PDG) como um conceito guardachuva para, a partir de uma demanda da comunidade ou de uma escolha temática, trabalhar-se um ou mais gêneros em um dado espaço de tempo, sempre com a preocupação de relacioná-lo a uma dada prática social. Este artigo apresenta o relato de experiência de uma professora desde a concepção até o desenvolvimento de seu PDG. Os resultados alcançados dão uma dimensão da possibilidade de superação das dificuldades de trabalho numa classe de alunos que vivem em situação de risco social, mas que merecem compartilhar práticas sociais que possibilitem sua inserção em diferentes domínios sociais.

\section{PALAVRAS-CHAVE}

Projeto didático de gênero. Letramento. Gênero textual. Formação continuada 


\section{PARA COMEÇO DE CONVERSA}

Este texto, ou na verdade, estes dois textos foram escritos por profissionais do ensino. Duas são trabalhadoras situadas no topo da pirâmide educacional, em um Programa de Pós-Graduação em Linguística Aplicada. Outra, trabalhadora na base da pirâmide, no Ensino Fundamental (EF). Mas todas participam de um mesmo projeto, sentam todas as terças pela manhã em uma mesa oval, com mais outros quinze profissionais, e refletem sobre possibilidades de ensino de Língua Portuguesa.

Todas acreditam que ser professor é uma profissão, não um dom, que precisa ser aperfeiçoada e (re)construída a cada interação com os alunos. Também entendem que os alunos podem ser muito diferentes, que sua relação com o mundo letrado, com as práticas sociais decorrentes da escrita, são muito variadas.

Hoje ainda ouvimos o relato da aquisição de uma palavra por uma criança de 20 meses, que nos deixou extremamente atentas para o fato de que a nova geração que ela representa viverá um fosso social talvez maior ainda pela frente. Vejam a cena: Tia Fafa, amiga da mãe do menino, também professora, tenta ensinar-lhe a palavra maçã. Havia feito isso com o vocábulo 'água', quando lhe deu um copo com água e o menino havia repetido a palavra com aquele prazer da descoberta da linguagem: á-ga. Trouxe-lhe, então, uma maçã, entregou em suas mãos e começou a falar: mAçã, mAçã. 0 menino pega a fruta nas mãos e fala: MAC. [MEC, como na pronúncia inglesa, na verdade]. Nem dois anos e já faz uma metonímia, tomando o símbolo da Apple como a palavra designadora da fruta.

Mas Deise, nossa professora do Ensino Fundamental, não tem alunos como esse. Seus alunos, na verdade, pouco contato têm com o mundo virtual. Suas vivências são muito mais de sobrevivência, para "não acabar no valão, com a boca cheia de formiga".

Acreditamos no trabalho com gêneros de texto. Desde 2003 temos desenvolvido pesquisas sobre o assunto, em ambientes sociais diversos. Mas, cada vez mais, olhando para as diversas realidades que compõem o mosaico das vidas em nosso País, pensamos que é imprescindível aliar o estudo de um gênero a uma prática social de letramento que possa ser válida além da esfera da escola. Para isso, o projeto que desenvolvemos atualmente concebeu o PDG - Projeto Didático de Gênero. Vamos contar um pouco desta história para depois Deise contar a sua. 
O projeto “Por uma formação continuada cooperativa para o desenvolvimento do processo educativo de leitura e produção textual escrita no Ensino Fundamental" conta com o apoio da Capes/ Programa Observatório da Educação (edital 2010) e tem o objetivo de aproximar reflexões produzidas/ em produção em nível acadêmico ao fazer profissional de docentes de Língua Portuguesa para, num processo cooperativo, alavancar o desempenho dos alunos no que diz respeito à leitura e escrita como práticas sociais. No desenvolvimento do projeto há dois parceiros comprometidos com concepções de educação, mais especificamente de ensino-aprendizagem de língua: o Programa de Pós-Graduação em Linguística Aplicada da Unisinos e a Secretaria Municipal de Educação de Novo Hamburgo - RS, cidade com 257.746 habitantes. As 76 escolas da rede municipal atendem 21.498 alunos no Ensino Fundamental e 4.889 na Educação Infantil.

Num primeiro olhar, a média do Ideb - Índice de Desenvolvimento da Educação Básica das escolas municipais de Novo Hamburgo não destoa muito dos resultados gerais do Estado do Rio Grande do Sul, considerandose a média de todas as escolas. Por outro lado, são até melhores do que os da rede municipal e os resultados gerais do Ideb para o restante do país. Há, entretanto, uma diferença importante: enquanto os resultados do Estado e do país apresentam tendência crescente, isso não se verifica nas escolas municipais de Novo Hamburgo, pois, na média, não houve mudanças nos resultados de 2007 e 2009. Em 2007 a média do primeiro segmento do Ensino Fundamental foi 4,8 e em 2009, 4,9; em 2007 e em 2009 a média do segundo segmento do Ensino Fundamental foi 3,7.

Apesar disso, quase a metade das escolas teve sua nota reduzida, o que aponta para o aprofundamento das diferenças entre as escolas. Por isso, ressaltamos a necessidade de ações também localizadas, mas efetivas, para a correção desse cenário.

Para mudar essa realidade pensamos um processo de formação continuada cooperativa, em que o letramento acadêmico dos formadores interaja com as práticas sociais dos professores e seus alunos, desenvolvendo, com nossos colaboradores, propostas didático-pedagógicas que formem um novo educador, apto ao manejo crítico do conhecimento e capaz de estar à frente dos desafios educacionais do terceiro milênio. Ao final de quatro anos esperase que cerca de 100 professores de Língua Portuguesa da Educação Básica e 
20 pós-graduandos estejam em ação na sala de aula com práticas renovadas e voltadas para a construção de objetos de ensino relacionados a leitura e produção textual, podendo, com isso, contribuir para a evolução dos índices oficiais do município.

Iniciamos o trabalho com a discussão de conceitos basilares para 0 desenvolvimento de proposta dessa natureza: concepções de linguagem, letramento, educação linguística e a noção de gênero, que serve como âncora para a coconstrução do que estamos denominando Projeto Didático de Gênero (PDG), como caracterizaremos adiante. Os professores conceberam projetos, a partir dos marcos conceituais com eles discutidos. 0 foco principal é a língua escrita, por entendermos ser esse o principal objetivo da escolaridade.

A partir do entendimento do grupo de Genebra, bastante conhecido no Brasil, de que "é através dos gêneros que as práticas de linguagem materializam-se nas atividades dos aprendizes" (SCHNEUWLY; DOLZ, 2004, p. 15), procuramos colocar a produção de leitura lado a lado com a produção textual, atribuindoIhes a mesma importância. Ampliamos, assim, o conceito de sequência didática. Entendemos leitura e escrita na perspectiva dos estudos de letramento: como práticas sociais que emergem de outras práticas da comunidade em que os alunos estão inseridos (BARTON; HAMILTON, 1998; KLEIMAN, 2008, OLIVEIRA, 2010). Os módulos ou oficinas pensadas para cada projeto pedagógico proposto trazem atividades de leitura que encaminham a produção textual.

Entendemos que o estudo das atividades de linguagem é feito através dos textos (orais e escritos) que as materializam. Tais textos são considerados unidades comunicativas globais (BRONCKART, 2004) e se agrupam em gêneros, "que são socialmente indexados, quer dizer, que são reconhecidos como pertinentes e/ou adaptados para uma situação comunicativa dada" (BRONCKART, 2004, p. 115). Entendemos que todo agir linguageiro se configura num texto pertencente a um determinado gênero e, por essa razão, julgamos importante o ensino através de gêneros. E se, com o trabalho com gêneros, queremos contribuir para o letramento dos alunos, assumimos, tal como Wells (2007) e Schneuwly e Dolz (2004), que a melhor maneira de ajudar os alunos a ler e a escrever é criar situações que impliquem ler e escrever para fins específicos, ou seja, a leitura e a escrita sendo necessárias para algo. Neste ponto os estudos de letramento nos auxiliam a dar um outro caráter ao trabalho com gêneros na escola.

As sequências didáticas (SD), tais como propostas por Schneuwly e Dolz (2004), aparecem como recortadas da realidade; em nosso grupo, entretanto, 
pensamos em projetos de gêneros que emerjam dessa realidade. O PDG abriga um conceito guarda-chuva para, a partir de uma demanda da comunidade ou de escolha temática, trabalhar-se um ou mais gêneros em um dado espaço de tempo (um bimestre, por exemplo), sempre com a preocupação de relacionálo(s) a uma dada prática social ${ }^{1}$.

Os documentos oficiais, como os Parâmetros Curriculares Nacionais (PCN) e os Referenciais Curriculares do Rio Grande do Sul, por exemplo, recomendam, em relação ao ensino de língua portuguesa, que o aluno seja inserido efetivamente no mundo da escrita e que suas possibilidades de participação social no exercício da cidadania sejam ampliadas. Isso, no nosso entender, acontecerá se ele for envolvido em situações linguisticamente significativas. Nesse sentido, o aluno deve ser engajado num projeto que seja seu, com o qual se identifique e que esteja ligado à cultura da comunidade de que faz parte (por isso a necessidade de o projeto ser coconstruído). Se entendemos que o letramento envolve as "práticas discursivas que precisam da escrita para torná-las significativas, ainda que às vezes não envolvam as atividades específicas de ler e escrever" (PCN, 1998, p.19), vemos que a sala de aula precisa dar conta da complexidade da comunicação contemporânea, o que nos faz assumir a existência de uma multiplicidade de letramentos associados a diferentes pessoalidades e identidades - que variam no tempo, no espaço e estão ligados a relações de poder (STREET, 1984; 2006; ROJO, 2009; KLEIMAN, 1995). Isso também nos faz pensar que, quanto menor for o grau de letramento das comunidades às quais os alunos pertencem, maior é a responsabilidade da instituição de ensino e dos professores para inseri-los e fazê-los transitar num mundo diferente do seu.

Nessa perspectiva, a noção de PDG tem um ou dois gêneros de texto/discurso como catalisador/es. Falamos e escrevemos através de gêneros, portanto essa não é uma tarefa que acontece apenas na escola. A escola é uma das esferas sociais em que um dado gênero circula (e, muitas vezes, de forma artificial). 0 desafio dos professores é conectar o gênero a outras esferas em que o aluno possa circular, esferas mais ou menos formais, em que possa vir a usar o gênero de que se apropriou. É necessário conectar também a escola à comunidade em que se acha inserida e às diferentes práticas sociais

0 trabalho proposto recebeu influência também dos chamados projetos de letramento (KLEIMAN, 2000; TINOCO, 2009), entendidos como práticas de letramento "que decorrem de um interesse real na vida dos alunos, servindo para atingir algum outro fim que vai além da mera aprendizagem da língua, no seu aspecto formal” (KLEIMAN, 2000, p. 238). Nesses projetos não há foco em um ou dois gêneros, e sim em tantos quantos forem necessários para se dar conta da demanda surgida na vida de alunos e professores. 
dessa comunidade, em que determinado gênero circula e, por essa razão, faz sentido para a vida do aluno.

A proposta é que o PDG represente uma coconstrução de conhecimento para uma prática social que possa se inscrever em situações significativas para os aprendizes e para seus docentes. Este projeto pode ser delineado a partir de diferentes entradas: um tema, uma prática social, um gênero mesmo do oral ou do escrito, um conteúdo gramatical. Estará necessariamente ligado a uma concepção que entende a linguagem como forma de interação, ou seja, como trabalho coletivo, social e historicamente situado e, por essa razão, orientado a uma finalidade específica, que se realiza nas práticas sociais existentes, nos diferentes grupos sociais de dada comunidade. Terá como características básicas: trabalhar a leitura (incluindo leitura do não-verbal) numa situação dialógica, numa atitude responsiva ativa (como propõem Volochinov, 2006 e Bakhtin, 2003) e focar, no máximo, dois gêneros, numa relação clara com as práticas sociais da comunidade à qual se destina. 0 projeto também se abre para a perspectiva interdisciplinar. Organizado em oficinas ou módulos, ocupará várias aulas, num trabalho sequencial, que incorporará toda a estrutura composicional do gênero trabalhado e vai se abrir para questões gramaticais que ajudem a produção do gênero em questão. Trabalhará, como afirmam Schneuwly e Dolz (2004), com a noção de que um gênero a ensinar também deve ser um gênero a comunicar. Uma produção inicial pode ser um passo importante para conhecer o que os alunos já entendem do gênero e virá a se constituir em parâmetro de avaliação no cotejo com a produção final. Para avaliar os textos produzidos pelos alunos, será construída, com eles, uma grade de avaliação com critérios coconstruídos em sala de aula.

Ler e escrever são atividades extremamente complexas, inseparáveis das pessoas e do local em que elas estão, da cultura em que se acham inseridas. Falar de leitura e escrita na escola implica falar daquela comunidade de aprendizagem (WELLS, 2006), do que significa ler e escrever aquele texto para aquele grupo. Pensar um projeto didático de gênero, portanto, é situá-lo social e historicamente, o que requer que o professor (ou o agente que vai desenvolvê-lo), ao pensar o letramento dos alunos, desenvolva um senso de lugar, de comunidade, que o leve a olhar para seus alunos e para o entorno, identificando os letramentos e as práticas comuns ali (ou ainda passíveis de serem desenvolvidas), enfim, os gêneros necessários para aquelas práticas. Cabe ao professor se perguntar constantemente "por que ensino o que ensino para estes alunos?" 
A pesquisa se caracteriza como pesquisa-ação, que entendemos colaborativa. Alicerçadas em Wells (2007), consideramos que a pesquisa colaborativa é o modo adequado de conduzir nossa investigação, porque pretendemos substituir a relação hierárquica e assimétrica entre quem faz pesquisa e quem a aplica (ou de quem se espera que a aplique), por uma relação de colaboração no contexto de sala de aula entre pesquisador e professor. Esse espaço de construção conjunto possibilita vivenciar o que o autor denomina de comunidade de indagação (WELLS, 2006). Para o autor, pensar a comunidade de indagação significa problematizar a prática escolar e refletir sobre ela. Nesse sentido, o professor que se propõe a refletir sobre sua prática e a investigar os processos de construção do conhecimento dos seus alunos (e o seu próprio) vai descobrindo novas possibilidades e significados naquilo em que faz/pensa, o que permite que ele vá se tornando também ele um pesquisador, o que, em nosso entender, é uma característica inerente à prática docente.

Nossa comunidade de indagação está constituída por seis representantes da rede municipal - cinco professores e uma coordenadora pedagógica -, três doutorandos, uma mestranda, oito bolsistas de iniciação científica e três pesquisadoras do Programa de Pós-Graduação em Linguística Aplicada da Unisinos. As comunidades de aprendizagem, hoje, consistem nas turmas dos cinco professores mencionados anteriormente.

0 projeto divide-se em etapas. Na primeira delas trabalhou-se com uma comunidade de indagação formada pelas pesquisadoras e bolsistas. $\mathrm{Na}$ segunda etapa abriu-se o projeto para aproximadamente 50 professores de Língua Portuguesa da rede municipal, em encontros presenciais. Tais professores seguem agora em encontros a distância, o que deverá ocorrer por dois anos, e formam uma segunda comunidade de indagação. Simultaneamente as reuniões com a primeira comunidade formada continuam, de forma a abastecer as discussões que ocorrem nos diferentes grupos. Essas etapas têm objetivos específicos.

Uma vez que, na missão de ensinar, o gênero não é apenas um instrumento de comunicação mas, ao mesmo tempo, um objeto de ensino/aprendizagem, concordamos com Schneuwly e Dolz (2004) que "quanto mais precisa a definição das dimensões ensináveis de um gênero, mais ela facilitará a apropriação deste como instrumento e possibilitará o desenvolvimento de capacidades de linguagem diversas que a ele estão associadas” (id, p.15). 
O ponto de partida dessa proposta é a transposição didática do gênero a ser ensinado, que passa pela definição dos princípios (por exemplo, o plano geral do gênero de texto escolhido), dos mecanismos enunciativos que se põem em ação e das formulações linguísticas, ou seja, os mecanismos de textualização, que devem constituir os objetos de aprendizagem dos alunos. Nessa proposta é importante assinalar que um dos seus objetivos é repensar a escolha dos objetos de ensino a serem enfocados pela escola. Trata-se de uma questão delicada, tendo em vista o "currículo oculto" que transparece na voz dos professores e que se refere, por exemplo, às classes gramaticais ensinadas per se, ou seja, para mero exercício classificatório. Assim, estamos percorrendo um percurso inverso para dar conta de novos objetos de ensino de língua curriculares, ou melhor, para dar funcionalidade aos objetos de ensino, que serão, então, também adequados às condições escolares e sociais dos alunos. Este é um desafio que enfrentaremos ao longo dos próximos semestres, quando estaremos trabalhando no estabelecimento de objetivos para as diferentes séries, de forma que haja uma progressão dos objetos a serem ensinados. Em outras palavras, estaremos repensando, junto com os professores, uma progressão curricular².

A proposta de trabalho com gêneros aqui defendida (cf. Guimarães, 2010) caminha nessa perspectiva: podem ser destacadas semelhanças de textos que pertencem a um mesmo gênero, mas cada gênero deve ser trabalhado por um determinado período de tempo, com ênfase em seus conteúdos específicos, que o diferenciam dos demais gêneros, sem perder de vista seu propósito comunicativo e seu espaço de circulação. Essa proposta concebe gêneros de texto como uma forma de articular as práticas linguageiras, entendendo-os como passíveis de serem aprendidos, mas, sobretudo, como formas de interação. Como afirmam Machado e Cristovão (2006, p. 561), "as atividades propostas por um determinado material didático destinado ao ensino de um gênero podem ser analisadas e avaliadas de acordo com as capacidades de linguagem que essas atividades permitem desenvolver: ou as capacidades de ação, ou as discursivas e/ou linguístico-discursivas”.

O relato a seguir dá conta dos passos iniciais da proposta de formação continuada cooperativa, que tem como base a noção de PDG. Deise é uma das

Observe-se que a progressão curricular não foi objetivo da primeira etapa de formação relatada neste artigo. Entendemos que precisávamos quebrar os paradigmas tradicionais de ensino de Língua Portuguesa através de mecanismos que permitissem ao professor reavaliar sua prática e ter confiança na nova proposta. Uma vez internalizada esta nova prática, será repensada a progressão curricular, considerando também os conhecimentos linguístico-discursivos. 
professoras da nossa comunidade de indagação. A escola onde trabalha está situada na periferia de Novo Hamburgo e tem 1.100 alunos. As famílias são pobres, muitas em situação de risco social. Os pais que trabalham exercem atividades pouco remuneradas (como faxineiras, pedreiros) e poucas famílias têm uma constituição tradicional. Muitos alunos têm padrasto, algumas mães são separadas ou solteiras; alguns moram com avós. Há problemas sérios de assiduidade, muito em função da situação social. Existe também grande rotatividade de professores, muito possivelmente em função de condições adversas de trabalho. Apesar de a escola oferecer um amplo espaço e diferentes ambientes, falta conservação desses espaços, pois falta a valorização do espaço físico da escola pelos próprios alunos, e, além disso, está sem manutenção e o prédio precisa de reparos.

Deise é uma professora com graduação em Letras que entrou há dois anos para a rede municipal, através de concurso público. Desenvolve 20 horas de trabalho. Desde janeiro é bolsista do Projeto, com o qual tem compromisso de 20 horas.

O trabalho relatado a seguir foi desenvolvido em três turmas de 6⿳a série, abrangendo um total de 93 alunos. Seu ponto de partida foi o gosto dos alunos de contar as tragédias do bairro, relacionadas à truculência de uma região metropolitana periférica, acrescido pelo fato de muitos alunos ficarem perturbados ao ouvir a palavra "policial”. A ficcionalização dessas tragédias poderia representar uma oportunidade de esses alunos refletirem sobre os problemas por que passam. Daí a escolha do gênero narrativa de detetive. Mas deixemos esse relato para Deise.

DE RELATOS ORAIS SOBRE CRIMES À PRODUÇÃO DE NARRATIVAS DE DETETIVE: TRANSFORMANDO LIMÕES EM LIMONADA

Com o objetivo de despertar o interesse dos meus alunos para a leitura e a escrita, desenvolvemos esse projeto de ensino. Digo que desenvolvemos, pois todo esse trabalho foi motivado pela nossa comunidade de indagação, que foi constituída na primeira etapa do programa de formação continuada. Os encontros semanais dessa comunidade foram fundamentais para que nós, professores, pudéssemos desconstruir nossas concepções de linguagem, de letramento, de ensino, e depois reconstruí-las, guiados pela permanente troca de experiências e fundamentados em um referencial teórico que pudesse nos respaldar para os passos seguintes, os desafios que teríamos de enfrentar. Além disso, foi nessa fase inicial que refletimos sobre o que estávamos 
realmente fazendo em sala de aula e o que gostaríamos de fazer, sobre quais caminhos deveríamos seguir para alcançar os objetivos traçados pelo Projeto Observatório.

Partindo do trabalho desenvolvido na comunidade de indagação, comecei a olhar minha realidade de sala de aula com outros olhos, permitindo-me amplificar, a cada encontro, minha visão sobre quem eram meus alunos e quais eram suas necessidades. Novas possibilidades me eram reveladas aos poucos, num processo em que não estava descobrindo apenas meus alunos, mas também estava desvendando minhas habilidades perdidas dentro da professora de Língua Portuguesa. No entanto, ainda não era fácil lidar com o contexto da minha escola, como ainda não é. Trabalho em uma escola de periferia, como tantos outros colegas de profissão por esse Brasil afora, onde a violência e a escassez de recursos são obstáculos enfrentados a cada dia. Em meio a uma comunidade bastante pobre, a escola é o único espaço em que os alunos encontram, além de alimentação, o lazer e um meio social mais saudável. As drogas fazem parte dessa realidade e, muitas vezes, relatos de alunos me mostraram que os traficantes figuram ora como vilões, ora como mocinhos, pois, ao mesmo tempo em que destroem os sonhos de juventude de muitos adolescentes, são eles que "protegem" a comunidade em certas ocasiões. A família não se faz presente na escola e, em diversas situações, quando se faz, revela desestrutura social e econômica na criação de seus filhos.

Desde que comecei a fazer parte da formação sabia que chegaria o momento em que teria que desenvolver um projeto de ensino, e isso me inquietava. Ele seria aplicado em minhas três turmas de 6aㅗ série do Ensino Fundamental. São 93 três alunos divididos nas três turmas, que assistem a quatro períodos de 55 minutos de Língua Portuguesa semanalmente. Esses alunos têm idade entre 12 e 15 anos. São turmas que apresentam alunos de características bem variadas, visto que, na formação dessas turmas, procurou-se misturar alunos com boas médias com outros de médias não tão boas, estudantes com problemas de comportamento com aqueles que têm atitudes exemplares, ou seja, nenhuma das turmas se distingue por algum aspecto específico.

O que poderia fazer para que meus alunos aderissem ao projeto? Seria capaz de realizar essa missão impossível, já que tantas vezes eu havia tentado novas propostas e não havia obtido sucesso?

Pensando em práticas anteriores é que, aos poucos, as ideias foram chegando. No ano anterior, a escola participou da Olimpíada de Língua Portuguesa 
Escrevendo o Futuro, que tinha como tema gerador "O lugar onde vivo". Com muita dificuldade apliquei as aulas propostas pelo projeto da Olimpíada, pois abordar esse assunto não era nada fácil. Os alunos não conseguiam ver aspectos positivos da comunidade. A cada aula que tentava trabalhar essa questão em sala, era bombardeada com histórias de assassinatos, de violência, de tiroteios. Tristes, alguns me contavam que os pais não os deixavam brincar na rua ou na casa de amigos, porque a insegurança os impedia. Outros, com maior liberdade por parte dos pais, eram os que mais sabiam sobre todo o tipo de violência que acontecia no bairro. Tive que buscar uma nova abordagem para concluir as atividades propostas, buscando na figura da escola (que eles apontaram como a coisa mais importante do bairro) uma luz no fim do túnel para a valorização do lugar onde eles viviam.

Lembrando de todos esses fatos percebi que já tinha muitos limões. Mas como fazer a limonada?

Nos encontros da formação com a comunidade de indagação discutíamos que nossos projetos deveriam ser elaborados utilizando um gênero textual como base, para que os alunos pudessem aprender de que forma esse gênero se constituía, construindo conceitos sobre o gênero para que, ao final das atividades, pudessem ser autores de textos desse gênero. $E$ eu, a cada terçafeira, perguntava-me: de que textos meus alunos gostariam de ser autores? Que gênero textual poderia ser útil para meus alunos, levando em conta o meio em que viviam? Como poderia despertar o interesse deles? De que forma eu poderia tratar aquela dura realidade de uma maneira lúdica?

Foram muitas (e necessárias) as perguntas até que eu começasse a encontrar uma saída. Após pensar e descartar diversos gêneros, percebi que um seria muito interessante justamente por aquela experiência vivida na Olimpíada. Se quando eu gostaria que eles me contassem histórias felizes eles me relatavam crimes, por que não pedir justamente que eles criassem histórias sobre os crimes?

Comecei a observar que meus alunos precisavam contar essas histórias. Quando enfrentamos situações que nos incomodam, nós as contamos várias vezes para conseguir assimilá-las. E era isso que meus alunos faziam, já que, mesmo não sendo nada agradável, acontecia no dia-a-dia, e eles precisavam encarar isso de alguma forma. Foi seguindo essa lógica que me convenci de que seria interessante trabalhar com narrativa de detetive. Através desse gênero os alunos poderiam reconstruir as histórias cotidianas de violência 
de uma maneira ficcional, utilizando a lógica para criar pistas, suspeitos, aguçando a imaginação e a criatividade.

A partir dessas ideias conversei com as turmas para saber o que achavam de trabalharmos com o gênero de narrativa de detetive nas aulas de Língua Portuguesa. Mesmo não sabendo ao certo o que eram narrativas de detetive, mostraram-se interessados. Contaram-me que costumavam assistir filmes e seriados sobre investigação criminal. Fiquei bastante contente com a resposta dos alunos, e foi nesse momento que decidi que esse seria o gênero com o qual seria elaborado o projeto de ensino, ou melhor, o PDG.

Escolhido o gênero textual que seria trabalhado, passei para a seleção dos textos. Essa parte da elaboração do projeto foi uma das mais difíceis, pois precisava encontrar textos que se enquadrassem como narrativas de detetive e se adequassem às preferências dos alunos. Entretanto, mais uma vez, não me faltou ajuda da nossa comunidade de indagação, já que, além de me sugerirem títulos e autores, os colegas me emprestaram livros, e acabei optando por uma dessas obras. Sei que quando não se tem a oportunidade de participar de uma formação cooperativa como a nossa fica mais difícil o trabalho em equipe, mas acredito que esse tipo de cooperação deva acontecer também dentro da escola, entre nossos colegas, não só entre os professores de Língua Portuguesa, mas também entre os demais professores.

A obra escolhida foi o livro "Os criminosos vieram para o chá", de Stella Car (2001). Escolhi esse título porque, além do suspense e da investigação criminal típica de uma narrativa de detetive, a história apresentava bastante humor. Contudo, algo ainda me incomodava; o cenário da narrativa era a nebulosa e fria Inglaterra de Sherlock Holmes, o investigador fazia parte da Scotland Yard e a principal suspeita era uma velhinha esquecida que tomava o chá das cinco com biscoitinhos e broinhas e admirava a gentileza dos guardas da rainha. Era um contexto completamente desconhecido para meus alunos. Ao apresentar esse receio para nosso grupo, outra vez, do diálogo e da troca, veio a solução. O filme de Sherlock Holmes (RITCHIE, 2009) caía como uma luva para apresentar aos estudantes o cenário onde se passaria a narrativa de detetive que eles leriam na sequência.

Dado o panorama de como surgiu a ideia do projeto de ensino e de como foi escolhido o texto base para seu desenvolvimento, passo agora a apresentar as oficinas elaboradas com os comentários e observações pertinentes.

O projeto foi dividido em três etapas: produção inicial, oficinas e produção final. 
Inicialmente expliquei aos alunos que essa seria a primeira aula de um projeto de ensino sobre o gênero narrativa de detetive e que, ao final desse projeto, eles escreveriam textos desse gênero para serem publicados na página da escola na Internet, para que fossem lidos pelos colegas da turma, da escola e por todos aqueles que tivessem interesse, visto que a página da escola não se restringe a seus discentes, mas é de domínio público. Logo após solicitei aos alunos a produção de um texto que correspondesse ao que eles conheciam sobre o gênero narrativa de detetive. Não houve maiores explicações sobre o gênero para que a produção demonstrasse os conhecimentos prévios sobre o gênero escolhido. Essa produção serviu de base para a observação dos pontos com necessidade de maior ênfase de trabalho em relação à estrutura do gênero e do tipo textual, assim como pontos de tópicos de linguagem que deviam ser trabalhados durante o projeto de ensino. Além disso, esse primeiro texto seria utilizado também na avaliação final, objetivando observar o progresso da produção do aluno dentro do gênero.

Comprovei nessa produção que meus alunos realmente se satisfaziam em serem autores desse gênero de texto. Mesmo não conhecendo todos os aspectos mais relevantes para o gênero, muitos deles colocaram bastante elementos adequados. Todavia observei que deveria ser trabalhada a criação de ambientes e de personagens que caracterizam as narrativas de detetive. Também percebi que seria fundamental trabalhar com a pontuação que, em muitos textos, simplesmente não era apresentada, e que o discurso direto e discurso indireto haviam sido utilizados de maneira inadequada. É interessante ressaltar que nem todos criaram textos narrativos, alguns alunos escreveram só o que eles achavam que era uma narrativa de detetive em vez de produzirem uma história com detetive.

\section{OFICINA 1 - CARACTERIZAÇÃO DO GÊNERO}

Para essa oficina foi utilizado o texto "O incrível enigma do galinheiro", de Marcos Rey (In: PRIETO, 1993). Foram analisadas as principais características do gênero e a estrutura da narrativa a partir de perguntas sobre o conhecimento que tinham do gênero, sua circulação, se apreciavam textos desse gênero.

Após isso eles responderam em seus cadernos perguntas relacionadas aos personagens e suas características, se haviam ouvido falar desse tipo de personagem, onde e quando ocorre a história e sua duração; perguntas em 
relação ao mistério, suspeitos, quem ia resolver o mistério, as estratégias usadas para desvendar o enigma, se havia pistas para resolver o mistério, se o mistério seria desvendado, se o aluno se surpreendera com a resolução e ainda sobre o narrador.

O questionário foi elaborado para que os alunos pudessem observar, nesse texto, as características gerais do gênero. Não foi fácil para eles realizarem essa análise, eles precisaram voltar diversas vezes ao texto e precisaram bastante da minha ajuda. Após respondidas as perguntas no caderno, corrigimos oralmente, momento em que pude esclarecer dúvidas que ainda restavam.

\section{OFICINA 2 - DISTINÇÃO ENTRE GÊNEROS TEXTUAIS}

Para essa oficina foi realizada a leitura da narrativa de detetive "O incrível enigma do galinheiro", da crônica literária "Conto de mistério" de Stanislaw Ponte Preta (PORTO, 2011) e de uma notícia sobre um crime misterioso veiculada na internet. 0 objetivo era que os alunos pudessem perceber que nem toda história com um mistério é uma narrativa de detetive. Nessa oficina foi fundamental a correção coletiva, realizada no quadro. Foi preenchido um quadro comparativo entre os três textos sobre a sua finalidade, seu suporte; a existência de enigma; as personagens e sua caracterização; o responsável pela resolução do mistério; o(s) suspeito(s); as pistas para solução do enigma; as ações dos personagens para essa solução; a resolução e a surpresa final.

\section{OFICINA 3 - SESSÃO DE VÍDEO}

Antes de iniciarmos a leitura do livro, os alunos assistiram a um filme do gênero narrativa de detetive, Sherlock Holmes (RITCHEI, 2009), para que pudessem compreender melhor o cenário em que se passa a história do livro. Procurei chamar a atenção dos alunos para as locações do filme, que mostravam os aspectos mais marcantes da Inglaterra, para que observassem a cultura inglesa presente tanto na obra fílmica quanto na obra literária que conheceriam na oficina seguinte.

\section{ATIVIDADE SIMULTÂNEA: DIÁRIO DE LEITURA}

Os alunos já estavam acostumados a registrar o que acontecia nas aulas de Língua Portuguesa e as suas impressões. Essa também foi uma prática que 
adotei com base nas experiências de meus colegas relatadas na comunidade de indagação. Ao iniciar a leitura do livro solicitei que o registro passasse a ser em relação à leitura do dia. Pedi aos alunos que fizessem um breve resumo do trecho lido, contando as partes da história que mais gostaram ou que não tivessem gostado e o que esperavam que acontecesse nos capítulos seguintes. Essa atividade possibilitou a ampliação da compreensão da história, pois, para resumi-la, era necessário que retomassem os pontos mais importantes. Além disso, a cada novo encontro, eles podiam retomar a leitura da aula anterior com uma olhadinha no diário.

OFICINA 4 - O TEMPO E O ESPAÇO

O livro “Os criminosos vieram para o chá”, de Stella Carr (2009), foi apresentado aos alunos, que se mostraram empolgados. Num primeiro momento, foram observadas as ilustrações internas e da capa sobre o espaço onde ocorre a história e lidos os capítulos 1 e 2 do livro. Em seguida, os alunos responderam em seus cadernos questões sobre quando ocorre a história, a identificação de informações relacionadas ao período em que ocorre a história e sua duração, a identificação de palavras relativas a tempo, caracterização do lugar onde ocorre a história.

\section{OFICINA 5 - COMEÇANDO SUA NARRATIVA}

Era a vez de os alunos pensarem na narrativa de detetive que criariam ao longo do projeto. Oralmente retomamos a história discutindo como o ambiente do crime do livro que estávamos lendo era caracterizado.

Em seguida, os alunos responderam a questões que os ajudariam a criar o espaço que ambientaria a narrativa de detetive. Receberam também um quadro a ser completado em relação ao tempo e espaço da história.

Por fim, foi-lhes solicitada a redação de um parágrafo em que deveriam descrever o ambiente onde ocorre a narrativa de detetive que seria escrita ao longo do projeto, lembrando-os de contar os detalhes do lugar que deixariam suas narrativas cheias de mistério.

Foram bastante interessantes os resultados dessa oficina: não foram poucos os relatos de becos escuros, com os sons desesperados emitidos por viciados, construções abandonadas que eram utilizadas como pontos de tráfico de drogas. Claro que nem todos criaram esse mesmo tipo de espaço, porém 
esses me marcaram, pois não eram relatos de uma realidade distante, dos filmes, era algo muito próximo deles.

\section{OFICINA 6 - O NARRADOR}

Nessa oficina foi realizada a leitura do capítulo 3 (1 a parte) do livro de Stella Carr (2009), seguida de questões orais e de exercícios sobre narrativa em $1^{\underline{a}}$ e $3^{a}$ pessoas e propondo mudança de foco narrativo na sua troca.

Precisei esclarecer um aspecto que já havia percebido e que causava uma confusão para os alunos. Quando eram questionados sobre quem era 0 narrador, os alunos sempre acabavam se referindo ao autor. Para isso, utilizei como exemplo um dos textos criados na produção dos alunos, cujo narrador era um delegado. Perguntei a eles se tinham como colega um delegado de polícia, rapidamente responderam-me que não. Assim expliquei que num dos textos criados por uma colega deles, o narrador era policial e contava a história que se passava em uma delegacia. Assim eles conseguiram entender que o autor era a colega deles, e que o narrador era também um personagem criado pela referida estudante.

\section{Oficina 7 - PERSONAgenS}

Para essa oficina foi realizada a leitura dos capítulos 4 e 5 (1ํa parte) do livro. Analisou-se os personagens apresentados até aquele momento na história.

Logo após os alunos realizaram diversas atividades relacionadas à caracterização das personagens e discutiram se as informações sobre os personagens responsáveis pelo roubo das joias ajudariam o leitor a revelar os mistérios da história. Depois disso os alunos criaram suas personagens, identificando o investigador, os criminosos ou suspeitos, o que os estimulou a pensar na narrativa de detetive que criariam ao longo do projeto. As personagens deveriam receber nomes e características.

Com essas atividades procurei chamar a atenção dos alunos para a importância da construção das personagens na criação do suspense e nas pistas que suas características representavam para que o mistério pudesse ser desvendado pelo leitor durante a leitura. Foi interessante perceber que as meninas estavam se identificando com a história, pois muitas criaram personagens femininas (tanto na figura dos suspeitos quanto na do detetive). 
Convidei um sargento da Brigada Militar para uma palestra, após a oficina em que o Sargento da Scotland Yard foi apresentado na narrativa como o detetive do crime investigado na história. Essa ideia nasceu na comunidade de indagação como forma de aproximar a história narrada à realidade dos alunos. Uma aproximação da polícia com a comunidade também se mostrava bastante importante, já que, como relatado anteriormente, no dia-a-dia deles por vezes os papéis se invertem, o traficante é que parece proteger e a polícia, que deveria servista como fonte de defesa, é que parece atacar a comunidade. O sargento mostrou, de maneira descontraída, quais são os passos de uma investigação criminal no Brasil, mostrando vídeos com reportagens sobre o tema e contando sobre o cotidiano dos profissionais responsáveis pela tarefa de investigar. Os alunos ficaram bastante envolvidos, prestando atenção a todos os detalhes ${ }^{3}$.

\section{OFICINA 9 - PERSONAgENS}

Foi discutida a personagem em torno da qual gira o enigma da história: Penélope (Miss Penny). Para isso, os alunos leram o capítulo 1 (2 ${ }^{\underline{a}}$ parte) do livro e realizaram as atividades, como expectativas criadas pelo título do capítulo, nome, apelido e características dessa personagem.

Também se levou os alunos a refletir sobre perguntas do texto ${ }^{4}$ que reforçavam uma característica de Miss Penny.

Os alunos gostaram muito desse trecho da história, pois, a partir dele, o mistério e o humor se tornam mais presentes. Simpatizaram bastante com Miss Penny, acho que por isso eles rapidamente responderam à tarefa com satisfação.

Infelizmente poucos alunos assistiram à palestra visto que justamente naquele dia ocorreu uma tempestade. 0 tempo e a temperatura que deveriam ser meros detalhes nas aulas, acabaram se mostrando obstáculos consideráveis para realização de projetos de longa duração. Em função da falta de recursos, em dias de inverno nos quais o frio é severo, muitos alunos faltam à aula, por não terem agasalhos suficientes para enfrentar tal situação. Em razão da localização do bairro onde os alunos moram, as casas facilmente alagam, e as crianças precisam ficar em casa nos dias de chuva forte para salvar seus pertences da água.

Por exemplo, "Sair de casa era um raro acontecimento, as compras semanais eram trazidas pelo Andrew. Agora era o filho dele. Ou seria o neto dele?" (p. 43) 


\section{Oficina 10 - Elementos Linguísticos}

Nessa oficina foi realizada a leitura do capítulo 2 ( $2^{\underline{a}}$ parte) do livro, seguido de questões que enfatizavam o uso de discurso direto e indireto. Para ajudálos a entender essa questão, no quadro, anotei as falas que estavam surgindo naquele momento e juntos fizemos as transformações de discurso direto para indireto e vice-versa.

\section{OFICINA 11 - PONTUAÇÃO}

Nessa oficina foi realizada a leitura do capítulo 3 (2 ${ }^{\mathrm{a}}$ parte).

Após a leitura fez-se uma atividade lúdica, objetivando chamar a atenção dos alunos para a necessidade de pontuação nos textos produzidos. Para isso utilizei um desafio que circula na Internet e recebi por e-mail algum tempo atrás. Utilizei a atividade abaixo, proposta pelo blog Simplesmente Português sobre o texto $O$ Mistério da Herança ${ }^{5}$.

Os alunos se empolgaram com o desafio, e em todas as turmas pelo menos um grupo chegou à resposta correta. A motivação de achar a resposta certa para o seu grupo ficou ainda maior quando souberam que haveria uma doce premiação para os que obtivessem sucesso na tarefa.

\section{OFICINA 12 - EXERCÍ́CIOS}

Nessa oficina ocorreu a leitura dos capítulos 4 e 5 ( 2 a parte). Logo após foram realizadas atividades de pontuação em duplas. Essas atividades têm como base as produções iniciais dos alunos, das quais foram retirados trechos não pontuados para que os alunos realizem a pontuação. Também foram extraídos dessas produções trechos em que a pontuação era presente, alguns corretamente, outros de maneira inadequada, para que os alunos pudessem identificar em quais trechos a pontuação é adequada. Como na maioria dos textos a pontuação não é utilizada, acredito que essas atividades reforçam a necessidade da pontuação observada na atividade proposta na oficina anterior.

Atividade disponivel em: http://simplesmenteportugues.blogspot.com/2010/05/ misterio-heranca-texto-trabalhar.html 
Nessa oficina foi realizada a leitura dos capítulos 1 e 2 (3aa parte).

Novamente os alunos trabalharam questões relacionadas à estrutura narrativa, procurando criar expectativas quanto ao final da história, sobre a revelação do mistério, sobre o próprio título do livro, fazendo-os imaginar outro título possível. Enfim, fiz uma retomada de toda a história, personagens, mistério, resolução do enigma, desfecho.

\section{OFICINA 14 - ROTEIRO PARA A PRODUÇÃO FINAL}

Foi realizada a leitura dos capítulos 3 e 4 (3aㅡ parte).

Nessa oficina foi proposta a elaboração coletiva de um roteiro para a produção final, com todas as características trabalhadas nas oficinas anteriores. Para isso foram abordadas oralmente algumas questões norteadoras em relação à estrutura narrativa, em relação às personagens, em relação ao narrador, em relação ao tempo e ao espaço, em relação aos discursos direto e indireto, em relação à estruturação das frases.

Durante essa abordagem oral, os aspectos tomados como essenciais foram anotados no quadro para que os alunos criassem seus roteiros para a produção de suas narrativas de detetive. Foi um momento fundamental para que pudessem relembrar as oficinas e, durante o passo seguinte, a produção final, pudessem colocar os conhecimentos adquiridos em prática.

\section{PRODUÇÃo FInAL}

Nesta última etapa do projeto foi a vez de os alunos mostrarem o quanto assimilaram os elementos constituintes do gênero textual para colocá-los em prática em suas produções. Após a escrita dessa produção aconteceu a correção entre os próprios alunos, usando como critérios o roteiro criado em aula e utilizado para a produção dos textos. Na sequência, houve a leitura do professor, momento em que foram feitas as sugestões de reescrita, para que então os textos ficassem prontos para serem postados na página da escola, como combinado no início do projeto.

Ainda que o que relatei aqui não seja algo absolutamente novo, acredito que tive bons resultados, pois grande parte das turmas estava atenta e motivada 
durante a realização das oficinas. Percebo que obtivemos grandes avanços, visto que, a cada aula que passava, via crescer o interesse dos meus alunos pela leitura, a curiosidade para desvendar os mistérios da trama. As turmas participantes eram muito agitadas, contudo em nenhum momento foi preciso mais que um pedido de atenção para que a leitura acontecesse. Isso pode parecer corriqueiro em outros contextos, mas não nessas turmas que normalmente reclamavam quando a leitura passava de uma folha; já durante o projeto, dez páginas eram lidas em algumas oficinas.

Sinto-me feliz porque estou realizando um trabalho útil para meus alunos e confiante de que eles alcançarão os objetivos traçados.

\section{AS POSSIBILIDADES SE SOBREPONDO ÀS DIFICULDADES}

Como um epílogo, podemos dizer que Deise já terminou seu trabalho e estamos, no momento, cotejando as produções finais de seus alunos com as produções iniciais, num processo de análise que deve ser levado a toda nossa comunidade de indagação. Transcrevemos na íntegra seu relato (que deve ser publicado em livro que estamos organizando sobre os primeiros resultados do projeto), pois entendemos que ela dá uma dimensão da possibilidade de superação das dificuldades de trabalho numa classe de alunos que vivem em situação de risco social, mas que merecem compartilhar práticas que possibilitem sua inserção social em diferentes domínios. Porque, como numa mensagem que circulou na internet no Dia do Professor:

As bolas de papel na cabeça

Os inúmeros diários para se corrigir

As críticas, as noites mal dormidas...

Tudo isto não foi suficiente

Para te fazer desistir do teu maior sonho

Tornar possíveis os sonhos do mundo.

Feliz Dia do Professor! 


\section{On the difficulties of the teaching profession as well as its possibilities}

\section{ABSTRACT}

Improving the performance of public school students in reading and writing skills is arising as one of the great challenges in the Brazilian school system. In partnership with the city of Novo Hamburgo-RS, we created a process of cooperative continuing education, in which the researchers' academic literacy interacts with the social practices of teachers and their students. In the project, we extended the concept of instructional continuance, teaching what we called the Educational Genre Project (PDG, its acronym in Portuguese) as an umbrella term so that, based on community demands or thematic choice, one or more genres could be worked on in a given space of time, always with the intention of relating it to a given social practice. This paper presents an account of a teacher's experience, from conception to development of her PDG. The results achieved provide an idea of the likelihood of possibly overcoming working difficulties in a class with students who live in at-risk environments, but who also deserve to share social practices that enable their inclusion into different social domains.

\section{KEYWORDS}

Educational genre project. Literacy. Text genre. Continuing education 


\section{REFERÊNCIAS}

KLEIMAN, Angela B.; SIGNORINI, I. (Orgs.) O ensino e a formação do professor. Alfabetização de jovens e adultos. Porto Alegre: Artmed, 2000. 248 p. p. 223243.

BAKHTIN, M. Estética da criação verbal. 4. ed. São Paulo: Martins Fontes, 2003.

BARTON, D.; HAMILTON, M. Local literacies: reading and writing in one community. New York: Routledge, 1998.

BRASIL. Parâmetros Curriculares Nacionais: Língua Portuguesa. Ministério da Educação e CULTURA. Secretaria da Educação Básica. - 3. e.d.. - Brasília: A Secretaria, 1998.

BRONCKART, J.P. Commentaires conclusifs: pour um développement collectif de l’interacionnisme socio-discursif. Calidoscópio 2(2): 113-23, jul-dez. 2004.

CARR, Stella. Os criminosos vieram para o chá. São Paulo: FTD, 2001. (Coleção um susto depois do outro)

KLEIMAN, Angela. B.. Os estudos de letramento e a formação do professor de língua materna. Linguagem em (Dis)curso, v. 8, p. 519-541, 2008.

KLEIMAN, Angela B. Modelos de letramento e as práticas de alfabetização na escola. In: KLEIMAN, Angela B. (Org.). Os significados do letramento. Campinas, S.P.: Mercado de Letras, 1995. 294 p. p. 15-61.

KLEIMAN, Angela B. O processo de aculturação pela escrita: ensino da forma ou

OLIVEIRA, Maria do Socorro. Gêneros textuais e letramento. RBLA, Belo Horizonte, v. 10, n. 2, p. 325-345, 2010.

PORTO, Sérgio (Stanislaw Ponte Preta). Conto de Mistério. Disponível em: $\langle$ 〈www.casadobruxo.com.br〉. Acesso em 20 de maio de 2011.

REY, Marcos. O incrível enigma do galinheiro. In: PRIETO, Heloísa (Org.) Viceversa ao contrário. São Paulo, Companhia da Letrinhas, 1993.

RIO GRANDE DO SUL. Referenciais Curriculares do Estado do Rio Grande do Sul: Linguagens, Códigos e suas Tecnologias/Secretaria de Estado da Educação. Porto Alegre: SE/DP, 2009. 
RITCHIE, Guy (Dir.). Sherlock Holmes. [Filme-vídeo]. Reino Unido / Austrália / EUA, Distribuidora Warner Bros, 2009. 128 minutos. Ação / Aventura.

ROJO, R. Letramentos múltiplos, escola e inclusão social. São Paulo: Parábola Editorial, 2009.

SCHNEUWLY, B. Gêneros e tipos de discurso: considerações psicológicas e ontogenéticas. In: SCHNEUWLY, B. \& J. DOLZ. Gêneros Orais e Escritos na Escola. Mercado de Letras. 2004, p. 21-40.

SCHNEUWLY, B.; J, DOLZ. Os gêneros escolares - das práticas de linguagem aos objetos de ensino. In: SCHNEUWLY, B.; J. DOLZ. Gêneros Orais e Escritos na Escola. Mercado de Letras, 2004. p. 71-94.

STREET, B. Perspectivas interculturais sobre o letramento. Trad. Marcos Bagno. Filologia e linguística portuguesa, São Paulo, no 8, 2006, p. 465-488.

STREET, Brian. Literacy in theory and practice. Cambridge: Cambridge University Press, 1984.

TINOCO, G. Usos sociais da escrita + projetos de letramento = ressignificação do ensino. In: GONÇALVES, A. e BAZARIM, M. (orgs.). Interação, gêneros e letramento: a (re)escrita em foco. São Carlos, Claraluz, 2009, p. 151-174.

VOLOCHINOV, M. Marxismo e filosofia da linguagem. 13 ed. São Paulo: Hucitec, 2006.

WELLS, G. Dialogic Inquiry as Collaborative Action Research. In: SOMEKH, S.; S. NOFFKE, B. (eds.) Handbook of Educational Action Research. Sage, 2007 Disponível em http://people.ucsc.edu/ gwells/Files/Papers_Folder/ Collaborative\%20Action\%20Research.pdf, acesso em 22.Ago.2009

WELLS, G. La unión de las dimensiones sociales, intelectuales y afectivas de la educación para transformar la sociedad. In: ALCALDE, A. I. et all. Transformando La escuela: las comunidades de aprendizaje. Barcelona: Editorial Grao, 2006, p. 19-28.

Recebido em: SETEMBRO de 2011

Aprovado em: NOVEMBRO de 2011 